\title{
Accelerated blood clearance phenomenon upon cross-administration of PEGylated nanocarriers in beagle dogs
}

\author{
Chunling Wang' \\ Xiaobo Cheng ${ }^{2}$ \\ Yuqing $\mathrm{Su}^{\prime}$ \\ Ying $\mathrm{Pei}^{3}$ \\ Yanzhi Song' \\ Jiao Jiao' \\ Zhenjun Huang' \\ Yanfei Ma' \\ Yinming Dong' \\ Ying Yao' \\ Jingjing Fan' \\ $\mathrm{Han} \mathrm{Ta}^{\prime}$ \\ Xinrong Liu' \\ Hui $X u^{\prime}$ \\ Yihui Deng' \\ 'College of Pharmacy, Shenyang \\ Pharmaceutical University, Shenyang, \\ People's Republic of China; ${ }^{2}$ Deli Wei \\ Biological Technology Co, Ltd, Beijing, \\ People's Republic of China; ${ }^{3}$ Shenyang \\ Women's and Children's Hospital, \\ Shenyang, People's Republic of China
}

Correspondence: Yihui Deng

College of Pharmacy, Shenyang

Pharmaceutical University,

103 Wenhua Road, Shenyang I 10016 ,

People's Republic of China

Tel +862423986316

Fax +862423986316

Email pharmdeng@gmail.com
This article was published in the following Dove Press journal:

International Journal of Nanomedicine

14 May 2015

Number of times this article has been viewed

Abstract: The cross-administration of nanocarriers modified by poly(ethylene glycol) (PEG), named PEGylated nanocarriers, a type of combination therapy, is becoming an increasingly important method of long-term drug delivery, to decrease side effects, avoid multidrug resistance, and increase therapeutic efficacy. However, repeated injections of PEGylated nanocarriers induces the accelerated blood clearance $(\mathrm{ABC})$ phenomenon, prevents long circulation, and can cause adverse effects owing to alterations in the biodistribution of the drug. Although the nature of the $\mathrm{ABC}$ phenomenon that is induced by repeated injections of PEGylated nanocarriers has already been studied in detail, there are few reports on the immune response elicited by the cross-administration of PEGylated nanocarriers. In this study, we investigated the ABC phenomenon induced by the intravenous cross-administration of various PEGylated nanocarriers, including PEGylated liposomes (PL), PEG micelles (PM), PEGylated solid lipid nanoparticles (PSLN), and PEGylated emulsions (PE), in beagle dogs. The results indicated that the magnitude of the immune response elicited by the cross-administration was in the following order (from the strongest to the weakest): PL, PE, PSLN, PM. It is specifically PEG in the brush structure that elicits a significant immune response, in both the induction phase and the effectuation phase. Furthermore, the present study suggests that there is a considerable difference between the effect of repeated injections and cross-administration, depending on the colloidal structure. This work is a preliminary investigation into the cross-administration of PEGylated nanocarriers, and our observations can have serious implications for the design of combination therapies that use PEGylated vectors.

Keywords: ABC phenomenon, repeated injection, cross-administration, immune response, PEGylated nanocarriers

\section{Introduction}

The term combination therapy refers to the simultaneous or successive use of either multiple pharmacologically active agents or different types of therapies such as chemotherapy and radiotherapy. ${ }^{1,2}$ Owing to the complex pathology of many diseases, combination therapy is increasingly used as a long-term therapy to reduce side effects and avoid multidrug resistance, ${ }^{1}$ and it is expected to become even more widespread in the future as an understanding of its underlying safety develops. ${ }^{3}$ Recent years have seen the development of therapies involving the cross-administration of two or more therapeutic agents using different nanocarriers. ${ }^{4,5}$ One such regimen developed to decrease the risk of complications and achieve maximum therapeutic efficacy is currently undergoing clinical trials. ${ }^{4}$ Although the use of multiple drugs can lead to new therapeutic possibilities, it can also make carrier design more complex and affect the safety of the carriers used. 
Nanoscale drug delivery systems, or nanocarriers, are widely used in both the clinic and the laboratory to enable passive drug targeting and decrease the harmful side effects of drugs. ${ }^{6-8}$ The surface of nanocarriers is frequently modified by attaching the polymer poly(ethylene glycol) (PEG) in a process called PEGylation. Such modified nanocarriers are able to avoid uptake by the mononuclear phagocyte system and have a correspondingly higher biological half-life; therefore, they are more likely to spontaneously accumulate in solid tumors via the enhanced permeability and retention effect. ${ }^{9,10}$ PEGylation was regarded as a major breakthrough in the development of nanocarriers, ${ }^{11}$ and offers new opportunities for cancer imaging, molecular diagnosis, and targeted therapy - especially combination therapy. ${ }^{12}$

However, Moghimi and Gray ${ }^{13}$ reported that particles that were coated with the amphiphilic polymer poloxamine lost their long-circulating characteristics after repeated injections at certain intervals. This phenomenon was named accelerated blood clearance (ABC) by Dams et al. ${ }^{14}$ This abnormal immune response has serious implications for the use of repeated injections of PEGylated nanocarriers and, as a result, has attracted a great deal of attention in the context of PEGylated liposomes (PL), ${ }^{14}$ PEGylated emulsions (PE), ${ }^{15}$ polymeric micelles, ${ }^{16}$ and PEGylated solid lipid nanoparticles (PSLN). ${ }^{17}$ Furthermore, it is worth noting that the intravenous administration of PEG micelles (PM) accelerated the plasma clearance of a subsequent dose of PEG liposomes, but did not influence the pharmacokinetics of a subsequent PM dose, suggesting that the ABC phenomenon may depend on the exact combination of nanocarriers used..$^{18}$

Although the induction of the $\mathrm{ABC}$ phenomenon by repeated injections of PEGylated nanocarriers has already been studied in detail, ${ }^{19}$ the immune response induced by the cross-administration of different PEGylated nanocarriers is not fully understood and a relevant systematic study is yet to be carried out. In this work, we investigated the effect of cross-administration on the $\mathrm{ABC}$ phenomenon by intravenously co-administering various PEGylated nanocarriers, including PL, PM, PSLN, and PE, in beagle dogs, and by comparing the magnitude of the $\mathrm{ABC}$ effect that was elicited by cross-administration and repeated injection. It is well known that the occurrence and the magnitude of the $\mathrm{ABC}$ phenomenon are influenced by physicochemical properties of PEGylated nanocarriers. ${ }^{19}$ To investigate the effect of cross-administration on the $\mathrm{ABC}$ phenomenon, the influencing factors should be fixed, for example, the PEG length and the encapsulated drug. Based on nanoparticles modified by 1,2-distearoyl-sn-glycero-3phosphoethanolamine- $N$-[methoxy (polyethylene glycol)2000] ( $\mathrm{mPEG}_{2000}$-DSPE), which exhibited prolonged blood circulation time and were widely applied in the clinical setup, ${ }^{20} \mathrm{mPEG}_{2000}$-DSPE was used to modify nanocarriers. Tocopheryl nicotinate (TN) was employed as an indicator by virtue of its lack of effect on the immune organs. Furthermore, the mechanism of the immune response induced by the cross-administration was further investigated, based on the anti-PEG IgM levels and the ability of anti-PEG IgM to bind to the PEGylated nanocarriers. Our work is an important preliminary investigation into the cross-administration of PEGylated nanocarriers, and our observations can have serious implications for the design of combination therapies that use PEGylated vectors.

\section{Materials and methods Materials}

TN was a gift from the Northeast Pharmaceutical Group Co., Ltd. (Shenyang, People's Republic of China). Injectable soybean lecithin (S75) was purchased from Lipoid GmbH (Ludwigshafen, Germany). Glycerin monostearate (GMS) and glycerol distearate (GDS) were supplied by SigmaAldrich (St Louis, MO, USA). Medium-chain triglycerides (MCT) were obtained from the Beiya Medicated Oil Co., Ltd. (Tieling, People's Republic of China). Cholesterol was provided by Nanjing Xinbai Pharmaceutical Co., Ltd. (Nanjing, People's Republic of China). PEE $_{2000}$-DSPE was supplied by Genzyme Corporation (Cambridge, MA, USA). All other reagents were of chromatographic grade.

\section{Animals}

Male beagle dogs weighing 10-12 kg were purchased from the Experimental Animal Center of Shenyang Pharmaceutical University (Shenyang, People's Republic of China). Animal care and experiments were performed in accordance with the Guide for the Care and Use of Laboratory Animals. ${ }^{21}$

\section{Preparation of various PEGylated nanocarriers}

\section{Preparation of PEGylated emulsions}

PE consisted of TN, MCT, and S75 (1:5:1.165, weight ratio). A 9:1 molar ratio of $\mathrm{S} 75$ to $\mathrm{mPEG}_{2000}$-DSPE was used.

Emulsions were prepared as previously described. ${ }^{15}$ Briefly, the oil phase (TN, MCT, S75, and $\mathrm{mPEG}_{2000}-\mathrm{DSPE}$ ) was constantly stirred in a water bath at $55^{\circ} \mathrm{C}$. The aqueous phase (sterile water) was heated to $55^{\circ} \mathrm{C}$ and added to the oil phase with rapid stirring. The emulsions were formed 
through agitation and incubation at $55^{\circ} \mathrm{C}$ for $10 \mathrm{~min}$. The mixture was sonicated in an ice bath using an ultrasonic cell pulverizer (JY92-II, Ningbo Scientz Biotechnology Co., Ltd., Zhejiang, People's Republic of China) at $200 \mathrm{~W}$ for $2 \mathrm{~min}$ and at $400 \mathrm{~W}$ for $6 \mathrm{~min}$. The resultant emulsions were sized by extruding through polycarbonate membrane filters with pore sizes of $0.22 \mu \mathrm{m}$ and were adjusted to an isotonic level by injecting $50 \%$ glucose.

\section{Preparation of PEGylated liposomes}

PL (TN:S75:cholesterol:mPEG ${ }_{2000}$-DSPE in a 3.9:5.4:3.6:1 molar ratio) was prepared using the thin film hydration method. Briefly, the lipid mixture was dissolved in ethanol, and the solvent was subsequently removed at $50^{\circ} \mathrm{C}$. The resultant dry lipid film was hydrated at $50^{\circ} \mathrm{C}$ in sterile water under mechanical agitation to obtain an injectable solution with a final lipid concentration of $41.6 \mathrm{mg} / \mathrm{mL}$. The resultant multilamellar vesicles were sonicated using a Vibracell probe sonicator (JY92-2D, Ningbo Xinzhi Biological Technology Co. Ltd., Ningbo, People's Republic of China) equipped with a tapered tip for at least $2 \mathrm{~min}$ at $200 \mathrm{~W}$, followed by sonication for $6 \mathrm{~min}$ at $400 \mathrm{~W}$. In order to remove large particles, the suspensions were passed through polycarbonate membrane filters with pore sizes of $0.8,0.45$, and $0.22 \mu \mathrm{m}$ after sonication, respectively.

\section{Preparation of PEGylated solid lipid nanoparticles}

Two solid lipid nanoparticle (SLN) preparations were used: PSLN-GMS and PSLN-GDS. They contained TN, GMS or GDS, S75, and $\mathrm{mPEG}_{2000}$-DSPE in a molar ratio of 7.5:56:9:1.

PSLN was prepared using the melt emulsification process, as previously described. ${ }^{22}$ Briefly, TN, GMS (or GDS), S75, and $\mathrm{mPEG}_{2000}$-DSPE (7.5:56:9:1, molar ratio) were mixed and dispersed in absolute ethanol at $65^{\circ} \mathrm{C}$, and then the solvent was removed. Sterile water was heated to $65^{\circ} \mathrm{C}$ and added to the mixture under mechanical agitation to give injectable solutions. Subsequently, the resultant mixture was treated using an ultrasonic cell pulverizer (JY92-II, Ningbo Scientz Biotechnology Co., Ltd.), for at least 2 min at $200 \mathrm{~W}$, followed by $3 \mathrm{~min}$ at $400 \mathrm{~W}$. Following sonication, the suspensions were sized through polycarbonate membranes with a pore size of $0.22 \mu \mathrm{m}$. The preparation was cooled to room temperature after the extrusion.

\section{Preparation of PEG micelles}

The TN-loaded $\mathrm{mPEG}_{2000}$-DSPE micelles were prepared using a self-assembly method. ${ }^{23} \mathrm{TN}$ and $\mathrm{mPEG}_{2000}$-DSPE (3:4, molar ratio) were dispersed in $0.5 \mathrm{~mL}$ of absolute ethanol, and sterile water was added to the homogeneous phase to achieve a clear, injectable micelle solution of volume $8 \mathrm{~mL}$. The final solution was filtered through a polycarbonate membrane with a pore size of $0.22 \mu \mathrm{m}$.

A submicron particle sizer (Nicomp 380 ${ }^{\mathrm{TM}}$, Particle Sizing Systems, Inc., Santa Barbara, CA, USA) was used to determine the mean diameters and zeta potentials of the emulsions, liposomes, SLNs, and micelles. Data are presented in Table 1.

\section{Determination of fixed aqueous layer thickness}

The fixed aqueous layer thicknesses (FALTs) of PE, PL, PSLN, and PM were determined using a common method based on the Gouy-Chapman theory. ${ }^{24-27}$ Zeta potentials were used to calculate the FALT using the following equation:

$$
\operatorname{Ln} \psi(L)=\operatorname{Ln} A-\kappa L
$$

where $A$ is a constant and $\kappa$ is the Debye-Huckel parameter, which is equal to $\sqrt{C} / 0.3$ for univalent salts, where $C$ is the molality of $\mathrm{NaCl}$. If zeta potentials are measured in various concentrations of $\mathrm{NaCl}$ and plotted against $\kappa$, the slope $L$ gives the positions of the slipping plane or thickness of the fixed aqueous layer in nanometers. Based on this theory, the thickness of the fixed aqueous layer of each nanoparticle was estimated.

Table I Characterization data of nanocarriers

\begin{tabular}{lllll}
\hline Formulation & Mean particle size $(\mathbf{n m})$ & PDI & Zeta potential $(\mathbf{m V})$ & FALT $(\mathbf{n m})$ \\
\hline PE & $126.8 \pm 3.2$ & $0.178 \pm 0.008$ & $-36.1 \pm 2.6$ & $3.5 \pm 0.2$ \\
PL & $132.8 \pm 6.2$ & $0.142 \pm 0.015$ & $-47.4 \pm 4.2$ & $3.3 \pm 0.1$ \\
PSLN-GDS & $137.3 \pm 4.9$ & $0.196 \pm 0.010$ & $-28.9 \pm 1.8$ & $2.8 \pm 0.4$ \\
PSLN-GMS & $123.8 \pm 2.8$ & $0.207 \pm 0.006$ & $-32.2 \pm 2.7$ & $2.1 \pm 0.2$ \\
PM & $14.3 \pm 1.4$ & $0.137 \pm 0.002$ & $-16.4 \pm 1.9$ & - \\
\hline
\end{tabular}

Notes: Data are mean \pm standard deviation of three repeats. "-" indicates that the value was not determined.

Abbreviations: PDI, polydispersity index; FALT, fixed aqueous layer thickness; GDS, glycerol distearate; GMS, glycerin monostearate; PE, PEGylated emulsions; PEG, poly(ethylene glycol); PL, PEGylated liposomes; PM, PEG micelles; PSLN, PEGylated solid lipid nanoparticles. 


\section{Pharmacokinetics of various PEGylated nanocarriers}

Male beagle dogs were randomly divided into 11 groups $(n=3)$. The injection protocols for the different PEGylated nanocarriers are presented in Table 2. The beagle dogs were treated with intravenous injections of various PEGylated nanocarriers at doses of $2.5 \mu \mathrm{mol}$ phospholipid $/ \mathrm{kg}$. The interval between the two injections was 7 days. At $1 \mathrm{~min}$, $3 \mathrm{~min}, 5 \mathrm{~min}, 10 \mathrm{~min}, 15 \mathrm{~min}, 0.5 \mathrm{~h}, 1 \mathrm{~h}, 2 \mathrm{~h}, 4 \mathrm{~h}, 6 \mathrm{~h}, 10 \mathrm{~h}$, and $24 \mathrm{~h}$ after the second injection, blood samples $(2 \mathrm{~mL})$ were taken and centrifuged at 4,000 rpm for $10 \mathrm{~min}$ to isolate the plasma. Plasma samples were stored at $-20^{\circ} \mathrm{C}$ until used.

\section{Measurement of TN concentration in plasma}

High-performance liquid chromatography (HPLC) was applied to determine the concentration of TN in the plasma by using a previously reported method. ${ }^{15}$ The HPLC system consisted of a P230 pump, a UV230 UV/Vis detector (Da Lian Elite Analytical Instruments Co., Ltd., Liaoning, People's Republic of China), and a Hypersil BDS C18 column $(5 \mu \mathrm{m}, 200 \times 4.6 \mathrm{~mm})$. Chromatographic conditions were as follows: mobile phase (methanol:isopropanol $=80: 20$, $\mathrm{v} / \mathrm{v})$, flow rate $(1 \mathrm{~mL} / \mathrm{min})$, column temperature $\left(30^{\circ} \mathrm{C}\right), \mathrm{UV}$ detector wavelength $(264 \mathrm{~nm})$. Before analysis, methanol $(100 \mu \mathrm{L})$, the internal standard $(100 \mu \mathrm{g} / \mathrm{mL}$ tocopheryl acetate; $100 \mu \mathrm{L})$, and $n$-hexane $(600 \mu \mathrm{L})$ were added to the plasma samples $(100 \mu \mathrm{L})$, and the mixture was vortexed for $5 \mathrm{~min}$. The supernatant $(500 \mu \mathrm{L})$ was obtained by centrifuging the mixture at 10,000 rpm for $10 \mathrm{~min}$ and dried using a CentriVap centrifugal vacuum concentrator (Labconco Corporation, Kansas City, MO, USA). Mobile phase

Table 2 Injection protocols used to administer nanocarriers to normal beagle dogs

\begin{tabular}{lll}
\hline Group & First treatment & Second treatment \\
\hline A & PE & PE \\
B & PL & PE \\
C & PSLN-GMS & PE \\
D & PSLN-GDS & PE \\
E & PM & PE \\
F & PE & PL \\
G & PE & PSLN-GMS \\
H & PE & PM \\
I & PSLN-GMS & PSLN-GMS \\
J & PM & PM \\
K & PL & PL \\
\hline
\end{tabular}

Abbreviations: GDS, glycerol distearate; GMS, glycerin monostearate; PE, PEGylated emulsions; PEG, poly(ethylene glycol); PL, PEGylated liposomes; PM, PEG micelles; PSLN, PEGylated solid lipid nanoparticles. (methanol:isopropanol $=80: 20, \mathrm{v} / \mathrm{v}, 100 \mu \mathrm{L}$ ) was used to dissolve the dried mixture. Then, the mixture was vortexed for $1 \mathrm{~min}$ and centrifuged at 10,000 rpm for $10 \mathrm{~min}$. The supernatant $(20 \mu \mathrm{L})$ was collected and used for the HPLC analysis.

\section{Detection of anti-PEG IgM antibodies in serum}

Anti-PEG IgM levels in serum were determined by the enzyme-linked immunosorbent assay (ELISA) method. ${ }^{28}$ A solution of $\mathrm{mPEG}_{2000}-\mathrm{DSPE}$ in absolute ethanol $(10 \mathrm{nmol}$; $50 \mu \mathrm{L}$ ) was added to a 96-well plate (Corning Incorporated, New York, NY, USA). The plate was then air dried and blocked for $1 \mathrm{~h}$ with $50 \mathrm{mM}$ Tris-buffered saline containing $0.14 \mathrm{mM} \mathrm{NaCl}$ and $1 \%$ bovine serum albumin (BSA; Biosharp, Seoul, South Korea). The plate was washed three times with washing solution ( $\mathrm{pH} 8.0$ Tris-buffered saline with $0.05 \%$ Tween $^{\circledR} 20$ [Sigma-Aldrich]). Diluted serum samples $(1: 1,000 ; 100 \mu \mathrm{L})$ were added to the 96 -well plate, which was incubated for $1 \mathrm{~h}$ and washed five times as described earlier. Goat anti-dog IgM was purchased from Immunology Consultants Laboratory, Inc (Portland, OR, USA), and conjugated to horseradish peroxidase (HRP) (obtained from Beijing Biosynthesis Biotechnology Co., Ltd., Beijing, People's Republic of China). The diluted HRP-conjugated goat anti-dog IgM antibody $(1 \mu \mathrm{g} / \mathrm{mL})$ was added to the 96-well plate and incubated for $1 \mathrm{~h}$. Then, the 96-well plate was washed five times. Staining was initiated by adding $o$-phenylene diamine $(100 \mu \mathrm{L} ; 1 \mathrm{mg} / \mathrm{mL}$, Sigma-Aldrich). The samples were then incubated for $15 \mathrm{~min}$, and the reaction was terminated by the addition of $\mathrm{H}_{2} \mathrm{SO}_{4}(100 \mu \mathrm{L} ; 2 \mathrm{~mol} / \mathrm{L})$. The absorbance was measured at $490 \mathrm{~nm}$ using a microplate reader (Bio-Rad Laboratories Ltd., Hertfordshire, UK). The experiment was performed at room temperature.

\section{Statistical analysis}

Data are presented as the mean \pm standard deviation. Statistical analysis was performed using Student's $t$-test with the SPSS 16.0 (SPSS Inc., Chicago, IL, USA) software. $P<0.05$ was considered statistically significant.

\section{Results The characteristics of various PEGylated nanocarriers}

It has been reported that the $\mathrm{ABC}$ phenomenon may be influenced by the physicochemical properties, for example, 

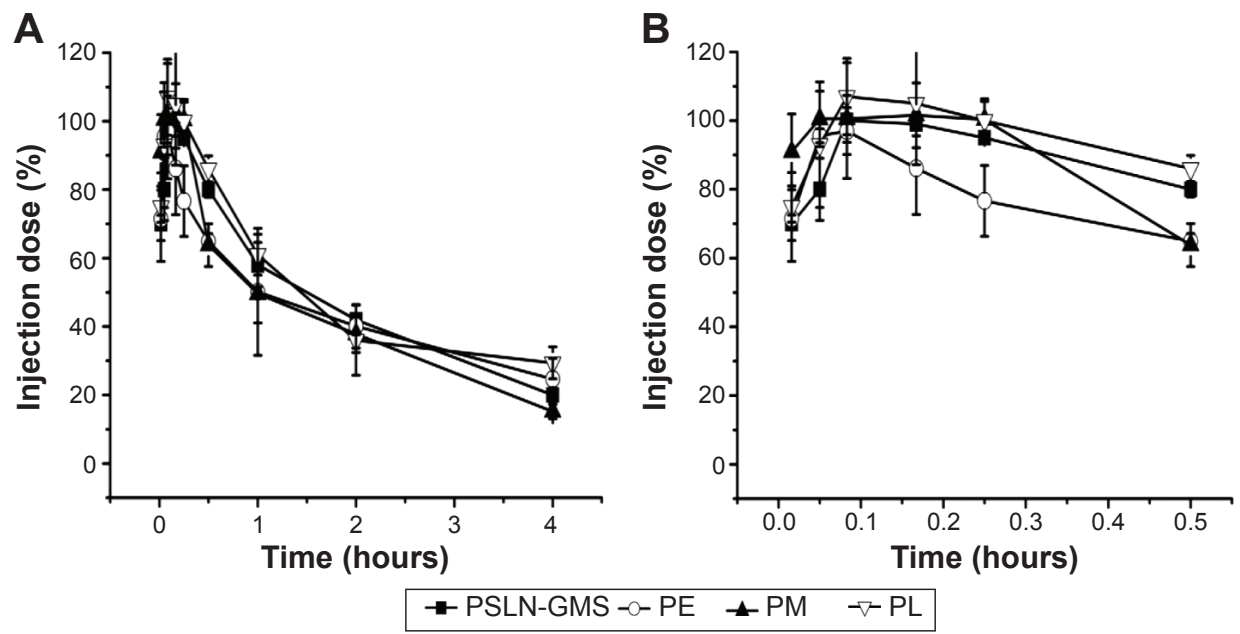

Figure I The blood clearance profile of a single intravenous injection of various PEGylated nanocarriers at a phospholipid dose of $2.5 \mu \mathrm{mol} / \mathrm{kg}$ in beagle dogs. Notes: Data shown over 0-4 hours (A). A magnified view of the 0-0.5 hour period (B). Data show mean \pm standard deviation of three repeats.

Abbreviations: GMS, glycerin monostearate; PE, PEGylated emulsions; PEG, poly(ethylene glycol); PL, PEGylated liposomes; PM, PEG micelles; PSLN, PEGylated solid lipid nanoparticles.

size, surface charge, degree of PEGylation, and PEG chain length of the nanocarrier that is injected first. ${ }^{29,30}$ Therefore, nanocarriers need to be fully characterized. Apart from PM, which measured $14.3 \pm 1.4 \mathrm{~nm}$, the mean particle size of the PEGylated nanocarriers was in the range of 120-140 nm. The FALTs of PEGylated nanocarriers were estimated based on the zeta potential data. In Table 1, the FALTs of PE, PL, PSLN-GMS, and PSLN-GDS, which contained $10 \mathrm{~mol} \%$ $\mathrm{mPEG}_{2000}$-DSPE, were determined to be $3.5 \pm 0.2,3.3 \pm 0.1$, $2.1 \pm 0.2$, and $2.8 \pm 0.4 \mathrm{~nm}$, respectively. The FALT of PM was not calculated, because the zeta potential of PM was almost not changed in the various concentrations of $\mathrm{NaCl}$. The particle size, polydispersity index, zeta potential, and FALT measurements of the PEGylated nanocarriers are summarized in Table 1.

\section{Pharmacokinetics of PEGylated nanocarriers following a single intravenous injection}

The beagle dogs were treated with PEGylated nanocarriers by an intravenous injection at a phospholipid dose of $2.5 \mu \mathrm{mol} / \mathrm{kg}$, and the pharmacokinetics was determined using HPLC. As shown in Figure 1, PEGylated nanocarriers exhibited a prolonged circulation time in the bloodstream and the plasma concentrations of PL, PE, PSLN-GMS, and $\mathrm{PM}$ at $4 \mathrm{~h}$ after the intravenous injection were $29.4 \% \pm 4.7 \%$, $26.7 \% \pm 6.1 \%, 20.1 \% \pm 2.1 \%$, and $15.2 \% \pm 2.1 \%$ of the injected dose, respectively. No statistical difference was found between the pharmacokinetic profiles of the first doses among the various PEGylated nanocarriers $(P>0.05)$.

\section{The immune response induced by the cross-administration of various PEGylated nanocarriers}

Effect of the cross-administration of PEGylated nanocarriers on the $A B C$ phenomenon in the induction phase

In order to investigate the inducement of the ABC phenomenon by cross-administration of PEGylated nanocarriers in the induction phase, the beagle dogs were administered the first injection of PEGylated nanocarriers (PE, PL, PSLN-GMS, or $\mathrm{PM}$ at a dose of $2.5 \mu \mathrm{mol}$ phospholipid $/ \mathrm{kg}$ ), and 7 days later the second dose of PE was administered. The results shown in Figure 2 indicate that the extent of the $\mathrm{ABC}$ effect depended on the type of PEGylated nanocarrier. PL and PE induced the fastest clearance of the second dose of PE. The percentage of injected TN remaining was less than $10 \%$ at 1 min after the second injection. The clearance of PE was moderately affected by the first injection of PSLN $\left(\mathrm{ABC}\right.$ index $\left.{ }_{(0-30 \mathrm{~min})}=0.42 \pm 0.08\right)$. In contrast, PM only slightly affected the subsequent dose of PE, especially at 0-30 min after the injection.

\section{Effect of the cross-administration of PEGylated nanocarriers on the $A B C$ phenomenon in the effectuation phase}

The beagle dogs were administered the first injection of PE (2.5 $\mu \mathrm{mol}$ phospholipid $/ \mathrm{kg})$, and 7 days later, a second injection of PE, PL, PSLN-GMS, or PM was administered. As shown in Figure $3 \mathrm{~A}$ and $\mathrm{B}$, the clearance rates of $\mathrm{PE}$ and PSLN were significantly faster when injected following a first injection of $\mathrm{PE}$ and the $\mathrm{ABC}$ indices $_{(0-30 \mathrm{~min})}$ were $0.05 \pm 0.00$ 


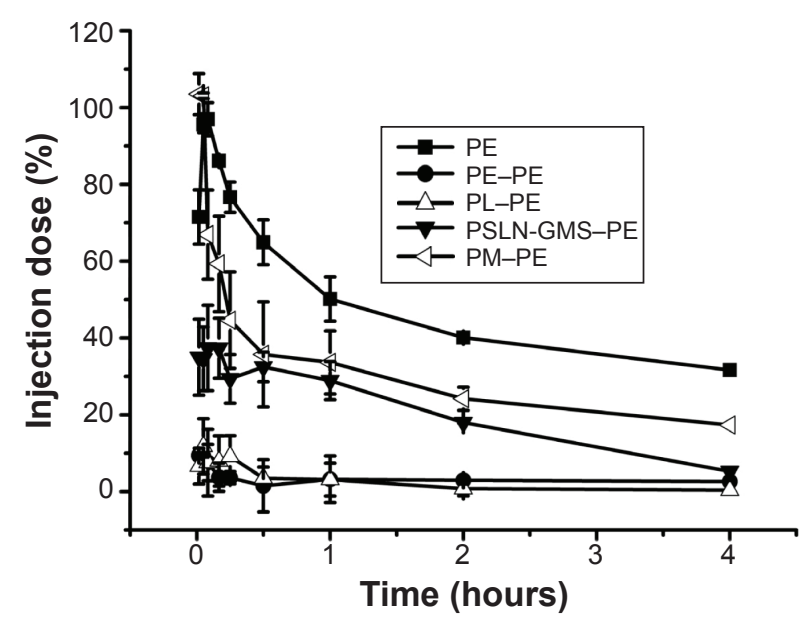

Figure 2 Effect of various PEGylated nanocarriers on the induction of the $A B C$ phenomenon in beagle dogs.

Notes: The beagle dogs were first given PE, PL, PSLN-GMS, or PM, at a dose of $2.5 \mu \mathrm{mol}$ phospholipid $/ \mathrm{kg}$. Then, 7 days after the first injection, the beagle dogs were given PE. Data show mean \pm standard deviation of three repeats.

Abbreviations: GMS, glycerin monostearate; PE, PEGylated emulsions; PEG, poly(ethylene glycol); PL, PEGylated liposomes; PM, PEG micelles; PSLN, PEGylated solid lipid nanoparticles. and $0.08 \pm 0.01$, respectively. In comparison with the second dose of PSLN-GMS, the blood clearance rate of the second dose of $\mathrm{PE}$ was faster $0-10$ min after the injection. The $\mathrm{ABC}$ phenomenon was less prominent in the case of PL (ABC index $\left._{(0-30 \mathrm{~min})}=0.18 \pm 0.04\right)$, and the pharmacokinetics of the second dose of PM was not affected by an initial administration of $\mathrm{PE}\left(\mathrm{ABC}\right.$ index $\left._{(0-30 \mathrm{~min})}=1.04 \pm 0.09\right)$.

\section{Comparison of the $\mathrm{ABC}$ phenomenon induced by the repeated injection and the cross-administration of various PEGylated nanocarriers}

In recent years, treatment regimens involving crossadministration have been widely used. Compared to the conventional repeated injections, this regimen results in significantly lower toxic side effects; furthermore, it reduces the risk of complications. As shown in Figure 4, the ABC phenomenon induced by repeated injection of various
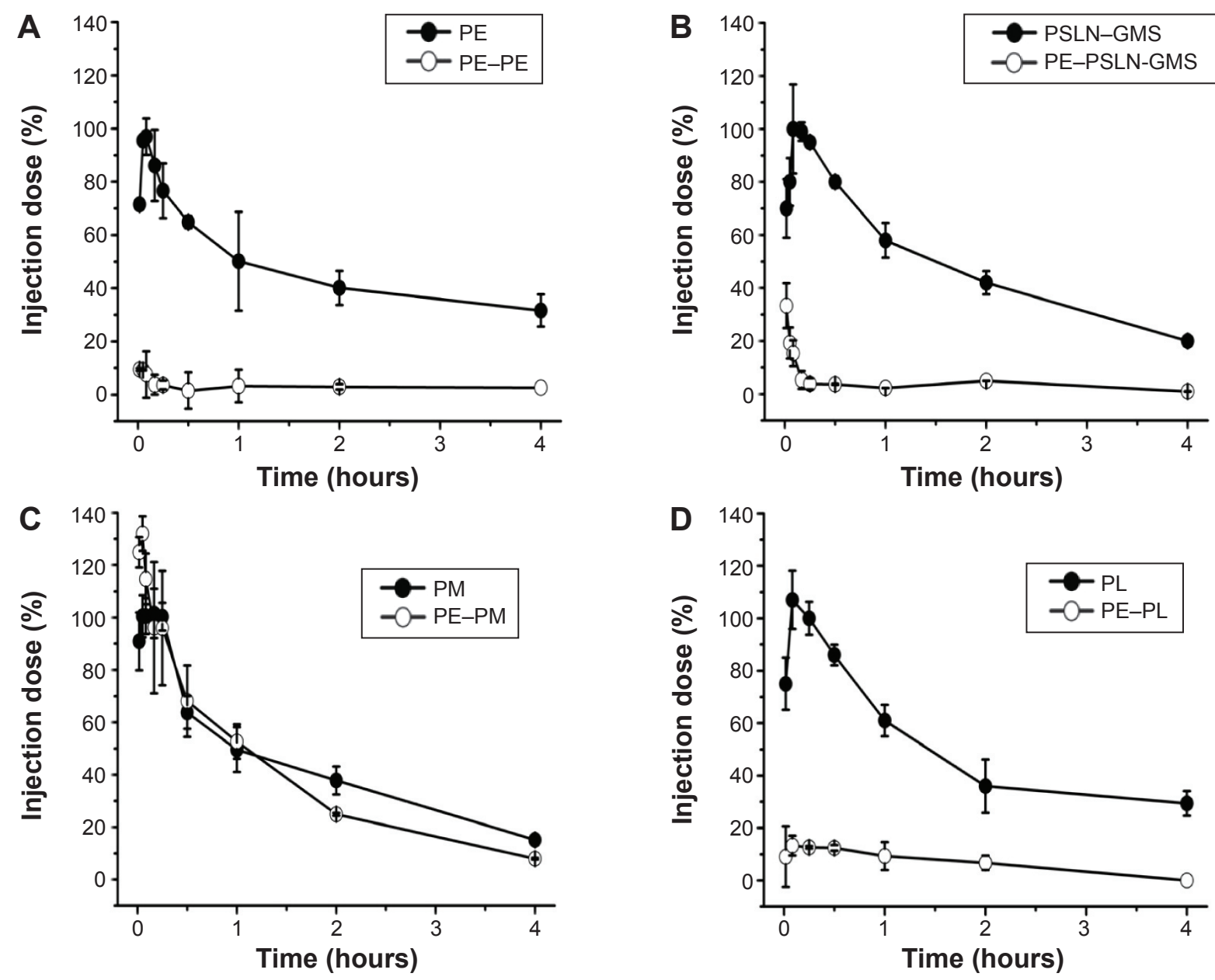

Figure 3 Effect of PE on the pharmacokinetics of various PEGylated nanocarriers in beagle dogs.

Notes: The beagle dogs were first given PE at a dose of $2.5 \mu \mathrm{mol}$ phospholipid/kg. Then, 7 days after the first injection, the beagle dogs were given PE (A), PSLN-GMS (B), PM (C), or PL (D). Data show mean \pm standard deviation of three repeats.

Abbreviations: GMS, glycerin monostearate; PE, PEGylated emulsions; PEG, poly(ethylene glycol); PL, PEGylated liposomes; PM, PEG micelles; PSLN, PEGylated solid lipid nanoparticles. 

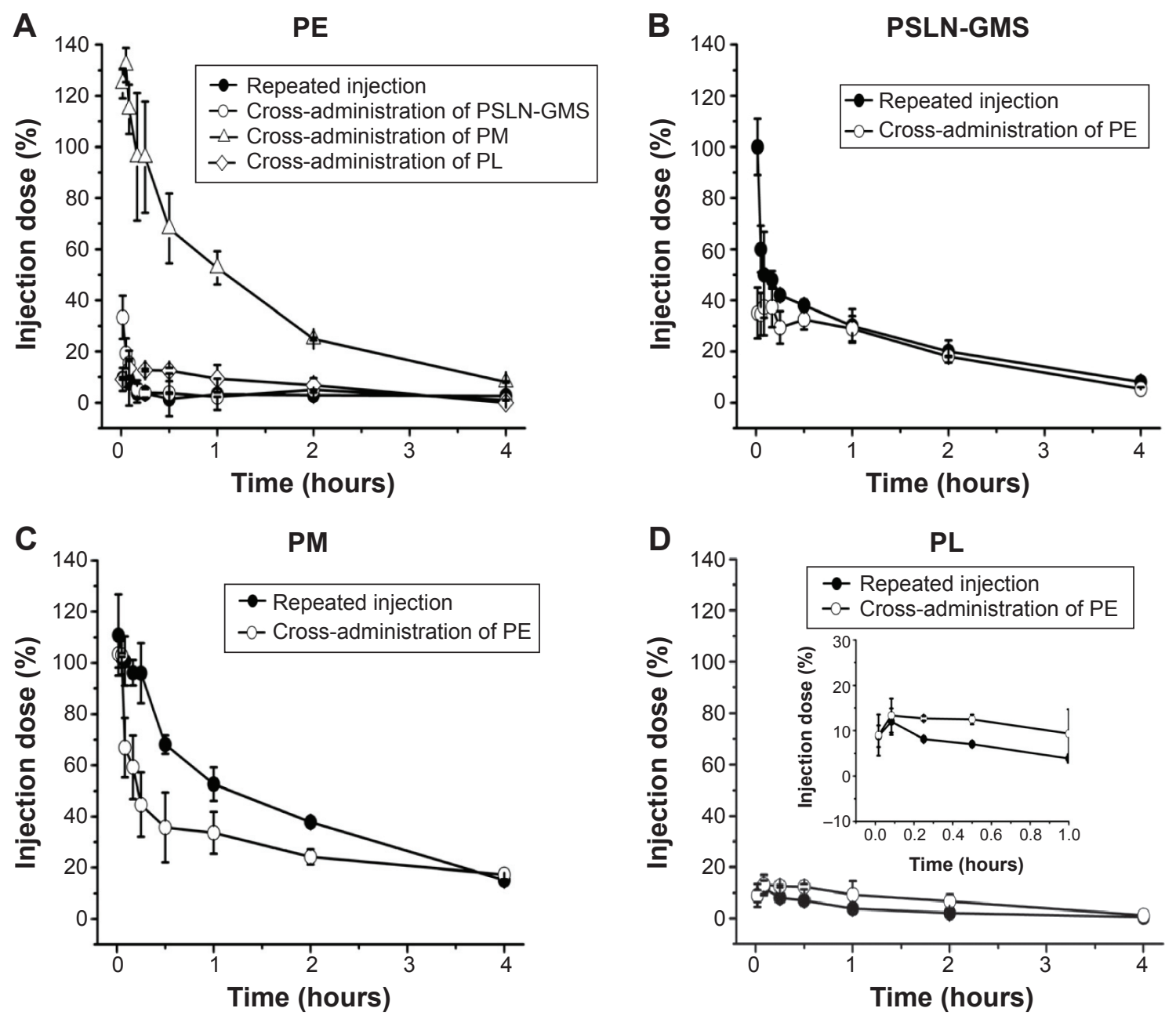

Figure 4 Comparison of the effects of repeated injections and cross-administration of various PEGylated nanocarriers on immune response.

Notes: PE (A); PSLN-GMS (B); PM (C); and PL (D). Data show mean \pm standard deviation of three repeats.

Abbreviations: GMS, glycerin monostearate; PE, PEGylated emulsions; PEG, poly(ethylene glycol); PL, PEGylated liposomes; PM, PEG micelles; PSLN, PEGylated solid lipid nanoparticles.

PEGylated nanocarriers was consistent with the results of previous literatures. ${ }^{14-17}$ Nevertheless, we found that the extent of the $\mathrm{ABC}$ phenomenon was different for repeated injections and cross-administration. It is difficult to accurately evaluate the extent of the immune response induced by repeated injections or cross-administration. Ishihara et a $^{31}$ calculated the ratio of the area under the curve $(\mathrm{AUC})_{(0-24 \mathrm{~h})}$ for the second injection to the $\mathrm{AUC}_{(0-24 \mathrm{~h})}$ for the first injection and referred to this as the $\mathrm{ABC}$ index; a value of 1 indicates no evidence of the $\mathrm{ABC}$ phenomenon. Moreover, our previous study proved that the ratio of $\mathrm{AUC}_{(0-30 \mathrm{~min})}$, regarded as the $\mathrm{ABC}$ index $\mathrm{(0-30 \textrm {min } )}$, was suitable for evaluating the $\mathrm{ABC}$ phenomenon, ${ }^{17}$ based on the fact that the $\mathrm{ABC}$ phenomenon is a rapid immune response. The results shown in Table 3 indicated that, for PE, the most marked $\mathrm{ABC}$ phenomenon was induced by repeated injections, followed by that induced by the cross-administration with PSLN-GMS; however, the blood clearance rate of PM was not affected by the first
Table 3 The ABC index ${ }_{(0-30 \mathrm{~min})}$ of repeated injections and crossadministration of various PEGylated nanocarriers

\begin{tabular}{ll}
\hline Group & ABC index ${ }_{(0-30 \mathrm{~min})}^{\mathrm{a}}$ \\
\hline Repeated injections & \\
PE-PE & $0.05 \pm 0.00^{* * *}$ \\
PSLN-GMS-PSLN-GMS & $0.51 \pm 0.03^{* *}$ \\
PM-PM & $0.99 \pm 0.08$ \\
PL-PL & $0.13 \pm 0.02^{* * *}$ \\
Cross-administration & \\
PL-PE & $0.09 \pm 0.00^{* * *}$ \\
PSLN-GMS-PE & $0.42 \pm 0.08^{* * *}$ \\
PM-PE & $0.68 \pm 0.05^{* *}$ \\
PE-PM & $1.04 \pm 0.09$ \\
PE-PSLN-GMS & $0.08 \pm 0.01^{* * *}$ \\
PE-PL & $0.18 \pm 0.04^{* * *}$ \\
\hline
\end{tabular}

Notes: ${ }^{a}$ The $A B C$ index ${ }_{(0-30 \mathrm{~min})}$ was calculated as follows: $A B C$ index ${ }_{(0-30 \mathrm{~min})}=$ $\mathrm{AUC}_{(0-30 \mathrm{~min})}$ of the second dose/AUC ${ }_{(0-30 \mathrm{~min})}$ of the single dose. Data are mean \pm standard deviation of three repeats. $P$-values represent a significant difference compared with I. $* * P<0.01$, *** $P<0.001$.

Abbreviations: $A B C$, accelerated blood clearance; AUC, area under the curve; GMS, glycerin monostearate; min, minutes; PE, PEGylated emulsions; PEG, poly(ethylene glycol); PL, PEGylated liposomes; PM, PEG micelles; PSLN, PEGylated solid lipid nanoparticles. 
injection of $\mathrm{PE}$. The $\mathrm{ABC}$ indices $_{(0-30 \mathrm{~min})}$ for the repeated injections and cross-administration of PSLN-GMS and PM were $0.05 \pm 0.00,0.08 \pm 0.01$, and $1.04 \pm 0.09$, respectively. For PSLN-GMS, cross-administration with PE induced a more pronounced $\mathrm{ABC}$ effect compared with repeated injections of PSLN-GMS (ABC index ${ }_{(0-30 \mathrm{~min}) \text { PSLN-PSLN }}=0.51 \pm 0.03$ and $\mathrm{ABC}$ index $\left._{(0-30 \mathrm{~min}) \mathrm{PSLN}-\mathrm{PE}}=0.42 \pm 0.08\right)$. It is worth noting the lack of $\mathrm{ABC}$ phenomenon that was observed when using PM. Repeated injections of PM failed to induce an ABC effect, but the ABC phenomenon was markedly observed in beagle dogs following cross-administration of PM and PE ( $\mathrm{ABC}$ index $\left._{(0-30 \mathrm{~min}) \mathrm{PM}-\mathrm{PE}}=0.68 \pm 0.05\right)$. In contrast, there was no statistical difference in the extent of the ABC phenomenon between repeated injections of $\mathrm{PL}$ and cross-administration of PE after PL, as evidenced by their $\mathrm{ABC}$ indices $_{(0-30 \mathrm{~min})}$ $(0.13 \pm 0.02$ and $0.09 \pm 0.00$ respectively).

\section{Level of anti-PEG IgM after treatment with various PEGylated nanocarriers}

Wang et $\mathrm{al}^{32}$ reported that the anti-PEG IgM production in the $\mathrm{ABC}$ phenomenon is involved in the accelerated clearance of the second dose. Thus, we determined the anti-PEG IgM levels produced by various PEGylated nanocarriers. In order to deduct the background value of different beagle dogs, the ratio of absorbance of anti-PEG $\operatorname{IgM}$ on day 7 (before the second injection) to that of anti-PEG IgM on day 0 (before the first injection) was used to evaluate the anti-PEG IgM level. As shown in Figure 5, for the cross-administration of PEGylated nanocarriers, the absorbance ratio of the anti-PEG

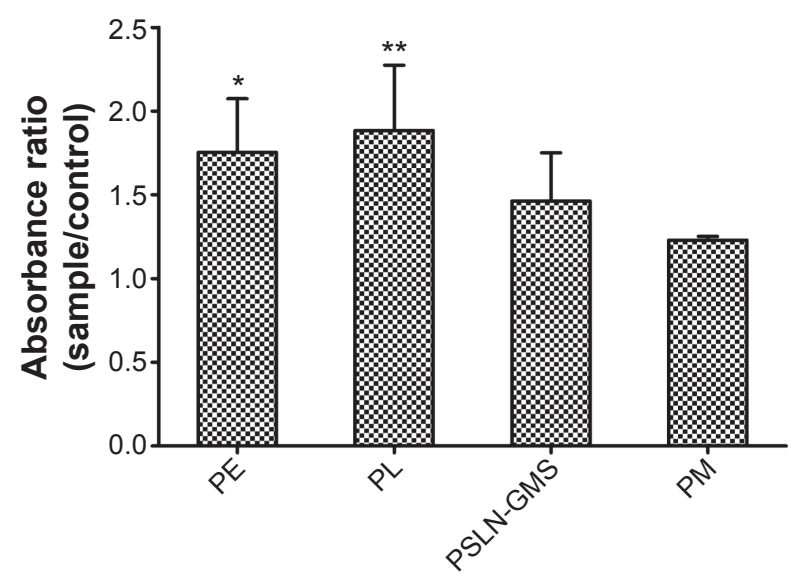

Figure $\mathbf{5}$ The production of anti-PEG IgM induced by the initial priming dose of various PEGylated nanocarriers (PE, PL, PSLN-GMS, and PM) at doses of $2.5 \mu \mathrm{mol}$ phospholipid/kg.

Notes: The anti-PEG IgM in the serum was determined using ELISA. Data show mean \pm standard deviation of three repeats. $P$-values represent a significant difference compared with I. $* P<0.05 ; * * p<0.01$.

Abbreviations: GMS, glycerin monostearate; ELISA, enzyme-linked immunosorbent assay; PE, PEGylated emulsions; PEG, poly(ethylene glycol); PL, PEGylated liposomes; PM, PEG micelles; PSLN, PEGylated solid lipid nanoparticles.
IgM ranked in the following order (from the highest to the lowest): PL, PE, PSLN-GMS, and PM.

\section{Discussion}

Generally, the first blood sample taken represents the maximum blood plasma concentration $\left(C_{\max }\right)$, because no absorption is required when injecting drugs directly into the bloodstream. Nevertheless, we found that the first blood sample taken 1 min after an intravenous injection of PEGylated nanocarriers in beagle dogs was not the maximum plasma concentration. The $\mathrm{C}_{\max }$ values of various PEGylated nanocarriers were observed for the third blood sample, which was taken 5 min after injection (Figure $1 \mathrm{~A}$ and B). The recognition and ultimate fate of foreign particles depends on the immune cells. ${ }^{33}$ In this study, the determination of blood cells at different time points after the injection of PE was used to monitor the real-time changes in blood immune cells, provide a quantitative measurement of this change, and reflect the interaction between the immune system and nanocarriers (see Supplementary material). The size and shape of nanocarriers are very similar to those of pathogenic microorganisms, subcellular organelles, and cell debris. ${ }^{34}$ The intravenous injection of PE was immediately recognized by the immune cells, and the immune cells migrated to the injected limb from the limb opposite to the injected limb. Subsequently, a large number of immune cells gathered around the injected PE and hindered its circulation from the injected limb to the opposite limb (from where the blood was taken). Therefore, the plasma concentration of PE was not at its maximum immediately after the intravenous injection. On the other hand, PEG coatings provide a steric barrier and prevent hydrophobic interactions between the surface of the nanocarriers and plasma opsonins, thus inhibiting their uptake by immune cells. ${ }^{35}$ Therefore, the plasma concentration of PE peaked at $5 \mathrm{~min}$ after the intravenous injection; meanwhile, the values of immune cells at the injection side and the side opposite to the injection site returned to the baseline levels (Figures S1A and B).

The ABC phenomenon that was induced by repeated injections of PEGylated nanocarriers is divided into two phases: the induction phase, following the first injection in which the immune system is primed and the anti-PEG IgM is produced, and the effectuation phase, following the second injection in which PEGylated nanocarriers are recognized, bound by the anti-PEG IgM, and rapidly cleared from the blood circulation. ${ }^{36}$ In this work, the immune response elicited by the cross-administration of PEGylated nanocarriers was investigated during the induction phase and the effectuation phase. 
Laverman et $\mathrm{al}^{36}$ proposed that the physicochemical properties of the second injection of nanoparticles influenced the magnitude of the $\mathrm{ABC}$ phenomenon. To investigate the effect of cross-administration of PEGylated nanocarriers on the immune response in the induction phase, beagle dogs were injected with PSLN, PL, PM, and PE, 7 days after the first injection; all groups were given PE. Although each type of PEGylated nanocarrier had a similar circulation time (Figure 1A), the blood clearance rate of the second dose of PE was completely different. As shown in Figure 2, the immunogenicity of the PEGylated nanocarriers in decreasing order was PL, PE, PSLN, and PM. A possible explanation is that the PEGylated nanocarriers have different colloidal structures. Different materials caused different types of binding proteins to be bound to different degrees. ${ }^{37}$ The lipids that make up the SLNs are solid at body temperature, which leads to the formation of tightly packed molecules in the emulsified layer. ${ }^{38}$ The hydrophobic regions of PSLN are not easily exposed, and this limits the extent of protein binding. Nevertheless, it cannot be ignored that PL, PE, PM, and PSLN-GMS had similar circulation times after intravenous injection (Figure 1A), and that this means that they have similar protein binding characteristics. Another explanation is related to the surface arrangements of PEG on nanocarriers. Koide et $\mathrm{al}^{16}$ reported that the $\mathrm{ABC}$ phenomenon was not observed in $\mathrm{BALB} / \mathrm{c}$ SCID (T- and B-cell-deficient) mice, but that anti-PEG IgM expression was induced in BALB/c nu/nu (T-cell-deficient) mice following treatment with PEGylated liposomes, suggesting that PEGylated liposomes elicit an anti-PEG IgM response in a T-cell-independent manner. Furthermore, Ishida et $\mathrm{a} \mathrm{l}^{39}$ proved that PEGylated liposomes promote an immune response against PEG in a manner similar to that induced by T-cell-independent type 2 (TI-2) antigens. In general, most TI-2 antigens have large multivalent molecules arranged on the surface and exhibit a prolonged circulation time in vivo. ${ }^{40,41}$ The ordered arrangement of polymer chains on the surface of PEGylated nanocarriers can interact with membrane receptors on B cells and induce a strong immune response. SLNs are defined as colloidal particles of lipid matrix that are solid at physiological temperature. ${ }^{42}$ Compared to liposomes and emulsions, it is difficult for SLNs to form a highly ordered crystal structure, ${ }^{43}$ leading to an irregular arrangement of PEG. Moreover, when the PEG on the surface of PSLN was arranged in a less orderly fashion, the ability of PSLN to activate B cells was diminished, resulting in the secretion of a small amount of anti-PEG IgM. Correspondingly, the ABC phenomenon induced by PSLNGMS was weaker than that by PL and PE.

In addition, the repeating $-\left(\mathrm{O}-\mathrm{CH}_{2}-\mathrm{CH}_{2}\right) n$ - subunit of PEG is the immunogenic epitope of PEGylated nanocarriers and a binding site for the derived anti-PEG IgM..$^{44,45} \mathrm{We}$ speculated that the observed differences in the extent of the $\mathrm{ABC}$ phenomenon are related to the PEG conformation on the surface of the different nanocarriers. Theoretically, in a nanoparticle prepared with less than $4 \mathrm{~mol}_{0} \mathrm{mPEG}_{2000^{-}}$ DSPE, the PEG on the nanoparticle surface is arranged in the mushroom conformation; with $4-8 \mathrm{~mol} \%$, it is in the transition conformation; and with more than $8 \mathrm{~mol} \%$, it is in the brush conformation. ${ }^{46}$ When PEG is arranged in the brush conformation, the neighboring PEG chains push against each other. In this study, in addition to PM, other nanocarriers contained $10 \mathrm{~mol}^{\%} \mathrm{mPEG}_{2000}-\mathrm{DSPE}$ at their surfaces, indicating that the PEG chains are arranged in the brush conformation. However, GMS, which formed the solid matrix of PSLN-GMS, contains two hydroxyl groups, which allows it to form hydrogen bonds with the oxygen atoms of PEG, and therefore, the PEG chains on the surface of PSLN-GMS tended to fold toward the surface and form the mushroom-like structures. In contrast, the grafted PEG on the surface of PL and PE was arranged in the brush configuration (Figure 6). We speculated that the repeat units of PEG are more exposed in the brush structure and, as a result, are more accessible to the
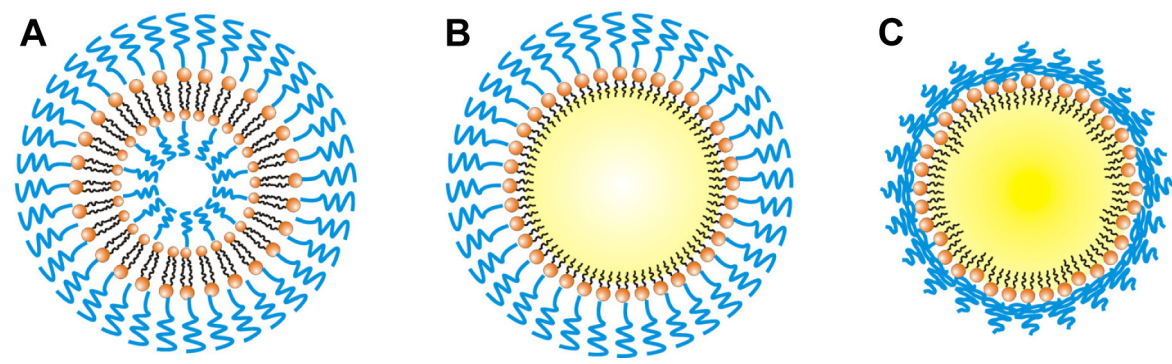

Figure 6 Diagram depicting the different PEG conformations on the surface of various nanocarriers.

Notes: PEG chains adopt a brush conformation on the surface of PE and PL, but have a mushroom-like conformation on the surface of PSLN-GMS. PL (A); PE (B), and PSLN-GMS (C).

Abbreviations: GMS, glycerin monostearate; PE, PEGylated emulsions; PEG, poly(ethylene glycol); PL, PEGylated liposomes; PSLN, PEGylated solid lipid nanoparticles. 


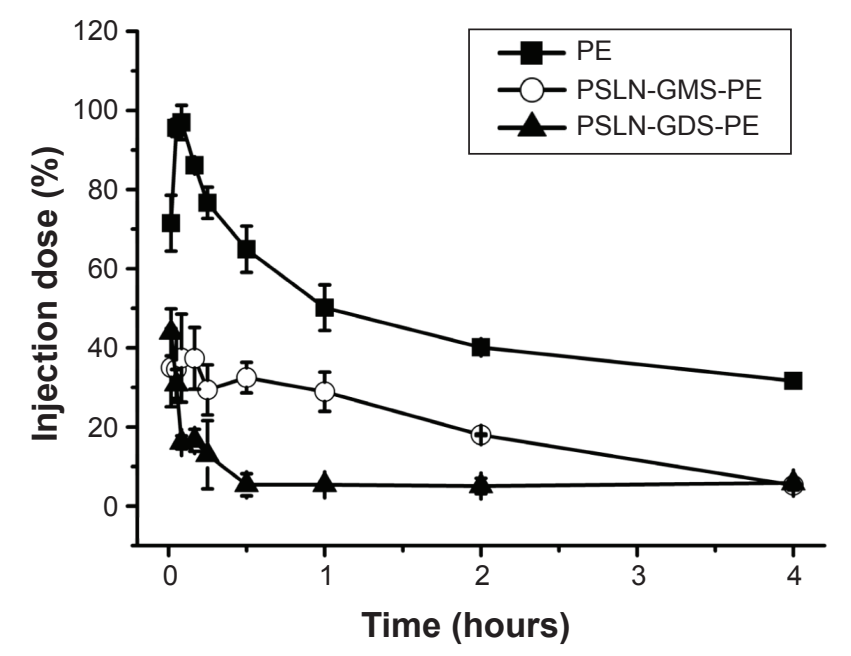

Figure 7 Effect of the types of lipid used to prepare PSLN on the induction of ABC phenomenon in beagle dogs. The beagle dogs were first given PSLN-GMS and PSLNGDS at a dose of $2.5 \mu \mathrm{mol}$ phospholipid $/ \mathrm{kg}$. Then, 7 days after the first injection, the beagle dogs were given PE. Data show mean \pm standard deviation of three repeats. Abbreviations: GDS, glycerol distearate; GMS, glycerin monostearate; PE,PEGylated emulsions; PEG, poly(ethylene glycol); PSLN, PEGylated solid lipid nanoparticles.

membrane receptors on $\mathrm{B}$ cells. In order to study the relationship between the conformation of PEG and immune response, the $\mathrm{ABC}$ phenomenon elicited by PSLN prepared with GMS, which contains two hydroxyl groups, was compared to that elicited by PSLN prepared with GDS, which contains one hydroxyl group. It was found that PSLN-GDS induced a faster blood clearance of the second-dose PE than did PSLN-GMS (Figure 7). Based on the modeling of PEG lipids by Needham et $\mathrm{al}^{47}$ the FALTs of nanocarriers were used to characterize the PEG chain length on the nanocarrier surface. We calculated the FALTs of PSLN-GMS and PSLN-GDS. The FALT data (Table 1) indicated that on the surface of PSLN-GMS, the PEG chain structure was more mushroom-like than brushlike, as evidenced by the thinner FALT for PSLN-GMS; this suggests that the PEG chains were more likely to fold toward the surface of PSLN-GMS. ${ }^{48}$ This result further indicated that nanocarrier surfaces featuring brush structure of PEG induce a significant $\mathrm{ABC}$ phenomenon.

It is well known that the size of particles has a considerable impact on the extent of PEG conjugation. In other words, the flexibility, surface density, and the FALT of the PEG layer are related to the size of the particles. Therefore, for small nanocarriers, the number of PEG chains per unit area is small, allowing the chains to be more flexible and the FALT to be thin. The particle size of PM was $14.3 \pm 1.4 \mathrm{~nm}$, which was much smaller than that of PL, PE, and PSLN. This means the PEG chains on the surface of PM were more flexible than those on PL, PE, and PSLN. Torchilin et al ${ }^{49}$ reported that the more flexible the PEG is, the more independent the motion of any polymeric unit relative to the neighboring one is. This means that the chains have a larger number of possible conformations and a higher transition rate from one conformation to another. The flexible PEG chains on the PM surface did not interact effectively with the B cells, and no significant level of anti-PEG IgM was observed (Figure 5). On the other hand, the molar percentage of $\mathrm{mPEG}_{2000}-\mathrm{DSPE}$ at the surface of PM was obviously greater than that at the surface of other PEGylated nanocarriers. Excessive cross-linking of membrane immunoglobulin was induced by the higher surface density of $\mathrm{PEG},{ }^{50}$ leading to B cells being not able to produce anti-PEG IgM. Nevertheless, our results indicated that the administration of PM accelerated the plasma clearance of the subsequent dose of $\mathrm{PE}$ and the $\mathrm{ABC}$ index ${ }_{(0-30 \mathrm{~min})}$ was $0.68 \pm 0.05$ (Figure 2). We speculated that the first injection of PM stimulated the activation of the liver macrophages (Kupffer cells) in an IgM-independent manner, resulting in the enhanced intrinsic phagocytosis and high response ability of Kupffer cells to the second injection of PE; however, further investigation is required to obtain a profound understanding of the mechanism of the immune response triggered by the cross-administration of PM and PE.

According to the two-phase model, the key factors influencing the magnitude of the $\mathrm{ABC}$ phenomenon are the level of anti-PEG IgM production in the induction phase and the binding of anti-PEG IgM to the PEGylated nanocarriers in the effectuation phase. In order to investigate the effect that cross-administration of PEGylated nanocarriers has on the $\mathrm{ABC}$ phenomenon in the effectuation phase, the beagle dogs were administered the first injection of PE (the equivalent anti-PEG IgM level), and 7 days later, a second dose of PE, PSLN-GMS, PM, or PL was administered. Interestingly, the clearance rates of PSLN-GMS, PL, and PE were significantly accelerated by the first injection of PE, and the blood removal rates of PE and PL were faster than that of PSLN 0-10 min after the second injection (Figure 3A and B). One possible explanation is that the various PEGylated nanocarriers induce the production of antibodies with different antigens-recognition abilities - the antigens that induced the antibodies were more strongly recognized by said antibodies. Nevertheless, the results shown in Figure 4B show that the blood clearance rate of the second injection of PE was still faster than that of PSLN 0-10 min after the first injection of PSLN-GMS. Another explanation is related to the PEG conformation on the surface of nanocarriers. Hashimoto et $\mathrm{al}^{51}$ reported that anti-PEG IgM that was generated in response to a single 
intravenous immunization of PEGylated liposomes had the ability to bind to the dense PEG that was mainly in a brush conformation. Compared with PSLN-GMS, the PEG chains in the PE formulation are more brush-like in structure; therefore, the anti-PEG IgM preferentially binds to the brush conformation of PEGylated nanocarriers. An exception is PM; the pharmacokinetics of the second-dose PM was not affected by an initial administration of PE (Figure 3C). The small particle size of PM was the reason it did not induce the $\mathrm{ABC}$ phenomenon. It is well known that IgM is the largest antibody and the molecular mass is $900 \mathrm{kDa}$, while the particle size of PM was only $14.3 \pm 1.4 \mathrm{~nm}$. The smaller-sized PM could avoid the binding by the anti-PEG IgM.

A comparative study of the ABC phenomenon elicited by the repeated injection and the cross-administration was carried out. Surprisingly, there is a considerable difference between the immune response induced by repeated injections and the response induced by cross-administration of PEGylated nanocarriers (Table 3). The $\mathrm{ABC}$ index ${ }_{(0-30 \mathrm{~min})}$ was used to evaluate the extent of the $\mathrm{ABC}$ phenomenon. According to the results of the statistical analysis of the $\mathrm{ABC}$ index $(0-30 \mathrm{~min})$, we propose that the $\mathrm{ABC}$ phenomenon can be classified into four types: significant $\mathrm{ABC}$ phenomenon ( $\mathrm{ABC}$ index $_{(0-30 \mathrm{~min})}$ was $\left.0.0-0.5\right)$, medium $\mathrm{ABC}$ phenomenon $\left(\mathrm{ABC}\right.$ index $_{(0-30 \mathrm{~min})}$ was $\left.0.5-0.7\right)$, weak $\mathrm{ABC}$ phenomenon $\left(\mathrm{ABC}\right.$ index $_{(0-30 \mathrm{~min})}$ was $\left.0.7-0.9\right)$, and no $\mathrm{ABC}$ phenomenon $\left(\mathrm{ABC}\right.$ index $_{(0-30 \mathrm{~min})}$ was $\left.0.9-1.0\right)$. For PE, repeated injections elicited the strongest $\mathrm{ABC}$ phenomenon $\left(\mathrm{ABC}\right.$ index $\left._{(0-30 \mathrm{~min})}=0.05 \pm 0.00\right)$, while the cross-administration of $\mathrm{PE}$ and either PSLN or PL induced a relatively weak $\mathrm{ABC}$ effect $\left(\mathrm{ABC}\right.$ indices $_{(0-30 \mathrm{~min})}$ were $0.08 \pm 0.01$ and $0.18 \pm 0.04$, respectively). Moreover, the cross-administration of PM elicited no immune response (ABC index $\left._{(0-30 \mathrm{~min})}=1.04 \pm 0.09\right)$. In contrast, for PSLN-GMS, the cross-administration of $\mathrm{PE}$ induced a stronger $\mathrm{ABC}$ phenomenon than repeated injections of PSLN-GMS (ABC indices $_{(0-30 \mathrm{~min})}$ were $0.42 \pm 0.08$ and $0.51 \pm 0.03$, respectively). It is worth noting that with repeated injections of PM, the first injection had no effect on the pharmacokinetics of the second; however, cross-administration of $\mathrm{PE}$ resulted in a medium $\mathrm{ABC}$ phenomenon $\left(\mathrm{ABC}\right.$ index $\left._{(0-30 \mathrm{~min})}=0.68 \pm 0.05\right)$. These results strongly indicated that the immune response induced by cross-administration is completely different from that induced by repeated injections. Thus, when combinations of different types of nanocarriers are used, the immune response is completely different. Therefore, it is necessary for us to systematically investigate the immune response triggered by cross-administration.

\section{Conclusion}

In this report, we demonstrate that an immune response is induced by the cross-administration of PEGylated nanocarriers (PE, PL, PSLN, and PM). The study indicated that in addition to $\mathrm{PM}$, nanocarriers with brush-like PEG structures could induce a significant ABC phenomenon. All else being equal, the anti-PEG IgM preferentially binds to PEGylated nanocarriers that have PEG chains in the brush conformation. For PM, the particle size played an important role in the attenuated $\mathrm{ABC}$ phenomenon by the cross-administration of $\mathrm{PE}$ and no immune response by repeated injections; however, further investigation is required to obtain a profound understanding of the mechanism. Importantly, there is a considerable difference between the $\mathrm{ABC}$ phenomenon induced by repeated injections and cross-administration. These findings provide novel insights into the methods that can be employed for reducing the immunogenicity of PEGylated nanocarriers. Furthermore, the results reported here have potential implications for the design, development, and clinical application of PEGylated products that require cross-administration.

\section{Acknowledgments}

This research was supported by the National Natural Science Foundation of China (Grant No 81072602) and the Shenyang Pharmaceutical University Students' Innovation Undertaking Project of Liao Ning Province (Grant No 201410163006).

\section{Disclosure}

The authors report no conflicts of interest in this work.

\section{References}

1. Greco F, Vicent MJ. Combination therapy: opportunities and challenges for polymer-drug conjugates as anticancer nanomedicines. Adv Drug Deliv Rev. 2009;61(13):1203-1213.

2. Broxterman HJ, Georgopapadakou NH. Anticancer therapeutics: "Addictive" targets, multi-targeted drugs, new drug combinations. Drug Resist Updat. 2005;8(4):183-197.

3. Gee J, Howell A, Gullick W, et al. Consensus statement. Endocr Relat Cancer. 2005;12(Suppl 1):S1-S7.

4. Honecker F, Kollmannsberger C, Quietzsch D, et al. Phase II study of weekly paclitaxel plus 24-h continuous infusion 5-fluorouracil, folinic acid and 3-weekly cisplatin for the treatment of patients with advanced gastric cancer. Anticancer Drugs. 2002;13(5):497-503.

5. Priotto G, Kasparian S, Mutombo W, et al. Nifurtimox-eflornithine combination therapy for second-stage African Trypanosoma brucei gambiense trypanosomiasis: a multicentre, randomised, phase III, noninferiority trial. Lancet. 2009;374(9683):56-64.

6. Suri SS, Fenniri H, Singh B. Nanotechnology-based drug delivery systems. J Occup Med Toxicol. 2007;2(1):16.

7. Farokhzad OC, Langer R. Impact of nanotechnology on drug delivery. ACS Nano. 2009;3(1):16-20.

8. Wagner V, Dullaart A, Bock A-K, Zweck A. The emerging nanomedicine landscape. Nat Biotechnol. 2006;24(10):1211-1218. 
9. Yuan F, Dellian M, Fukumura D, et al. Vascular permeability in a human tumor xenograft: molecular size dependence and cutoff size. Cancer Res. 1995;55(17):3752-3756.

10. Laginha K, Mumbengegwi D, Allen T. Liposomes targeted via two different antibodies: assay, B-cell binding and cytotoxicity. Biochim Biophys Acta. 2005;1711(1):25-32.

11. Storm G, Belliot SO, Daemen T, Lasic DD. Surface modification of nanoparticles to oppose uptake by the mononuclear phagocyte system. Adv Drug Deliv Rev. 1995;17(1):31-48.

12. Nie S. Understanding and overcoming major barriers in cancer nanomedicine. Nanomedicine. 2010;5(4):523-528.

13. Moghimi SM, Gray T. A single dose of intravenously injected poloxamine-coated long-circulating particles triggers macrophage clearance of subsequent doses in rats. Clin Sci. 1997;93(4):371-379.

14. Dams ET, Laverman P, Oyen WJ, et al. Accelerated blood clearance and altered biodistribution of repeated injections of sterically stabilized liposomes. J Pharmacol Exp Ther. 2000;292(3):1071-1079.

15. Wang C, Cheng X, Sui Y, et al. A noticeable phenomenon: thiol terminal PEG enhances the immunogenicity of PEGylated emulsions injected intravenously or subcutaneously into rats. Eur J Pharm Biopharm. 2013; 85(3):744-751.

16. Koide H, Asai T, Hatanaka K, et al. Particle size-dependent triggering of accelerated blood clearance phenomenon. Int J Pharm. 2008; 362(1-2):197-200.

17. Zhao YX, Wang L, Yan MN, et al. Repeated injection of PEGylated solid lipid nanoparticles induces accelerated blood clearance in mice and beagles. Int J Nanomedicine. 2012;7:2891-2900.

18. Kaminskas LM, Mcleod VM, Porter H, Christopher J, Boyd BJ. Differences in colloidal structure of PEGylated nanomaterials dictate the likelihood of accelerated blood clearance. J Pharm Sci. 2011; 100(11):5069-5077.

19. Abu Lila AS, Kiwada H, Ishida T. The accelerated blood clearance (ABC) phenomenon: clinical challenge and approaches to manage. J Control Release. 2013;172(1):38-47.

20. Pozzi D, Colapicchioni V, Caracciolo G, et al. Effect of polyethyleneglycol (PEG) chain length on the bio-nano-interactions between PEGylated lipid nanoparticles and biological fluids: from nanostructure to uptake in cancer cells. Nanoscale. 2014;6(5):2782-2792.

21. US Department of Health and Human Services; Public Health Service; National Institutes of Health. Guide for the Care and Use of Laboratory Animals. Washington, DC: National Academy Press; 1985.

22. Zhao YX, Wang CL, Wang L, et al. A frustrating problem: accelerated blood clearance of PEGylated solid lipid nanoparticles following subcutaneous injection in rats. Eur J Pharm Biopharm. 2012;81(3): 506-513.

23. Song H, Geng H, Ruan J, et al. Development of Polysorbate 80/ Phospholipid mixed micellar formation for docetaxel and assessment of its in vivo distribution in animal models. Nanoscale Res Lett. 2011;6(1):1-12.

24. Shimada K, Miyagishima A, Sadzuka Y, et al. Determination of the thickness of the fixed aqueous layer around polyethyleneglycol-coated liposomes. J Drug Target. 1995;3(4):283-289.

25. Sadzuka Y, Nakade A, Tsuruda T, Sonobe T. Study on the characterization of mixed polyethyleneglycol modified liposomes containing doxorubicin. J Control Release. 2003;91(3):271-280.

26. Sadzuka Y, Nakade A, Hirama R, et al. Effects of mixed polyethyleneglycol modification on fixed aqueous layer thickness and antitumor activity of doxorubicin containing liposome. Int J Pharm. 2002;238(1):171-180.

27. Wilson DR, Zhang N, Silvers AL, Forstner MB, Bader RA. Synthesis and evaluation of cyclosporine A-loaded polysialic acidpolycaprolactone micelles for rheumatoid arthritis. Eur J Pharm Sci. 2014;51:146-156.

28. Ichihara M, Shimizu T, Imoto A, et al. Anti-PEG IgM response against PEGylated liposomes in mice and rats. Pharmaceutics. 2010; 3(1): $1-11$
29. Ishida T, Ichikawa T, Ichihara M, Sadzuka Y, Kiwada H. Effect of the physicochemical properties of initially injected liposomes on the clearance of subsequently injected PEGylated liposomes in mice. J Control Release. 2004;95(3):403-412

30. Wang XY, Ishida T, Ichihara M, Kiwada H. Influence of the physicochemical properties of liposomes on the accelerated blood clearance phenomenon in rats. $J$ Control Release. 2005;104(1):91-102.

31. Ishihara $\mathrm{T}$, Takeda $\mathrm{M}$, Sakamoto $\mathrm{H}$, et al. Accelerated blood clearance phenomenon upon repeated injection of PEG-modified PLA-nanoparticles. Pharm Res. 2009;26(10):2270-2279.

32. Wang X, Ishida T, Kiwada H. Anti-PEG IgM elicited by injection of liposomes is involved in the enhanced blood clearance of a subsequent dose of PEGylated liposomes. J Control Release. 2007;119(2):236-244.

33. Janeway CA, Travers $\mathrm{P}$, Walport M, Shlomchik MJ. Immunobiology. New York, NY: Garland Science; 2001:910.

34. Szebeni J, Muggia F, Gabizon A, Barenholz Y. Activation of complement by therapeutic liposomes and other lipid excipient-based therapeutic products: prediction and prevention. Adv Drug Deliv Rev. 2011;63(12):1020-1030.

35. Owens DE III, Peppas NA. Opsonization, biodistribution, and pharmacokinetics of polymeric nanoparticles. Int J Pharm. 2006;307(1):93-102.

36. Laverman P, Carstens MG, Boerman OC, et al. Factors affecting the accelerated blood clearance of polyethylene glycol-liposomes upon repeated injection. J Pharmacol Exp Ther. 2001;298(2):607-612.

37. Jiskoot W, van Schie RM, Carstens MG, Schellekens H. Immunological risk of injectable drug delivery systems. Pharm Res. 2009;26(6): 1303-1314.

38. Müller R, Radtke M, Wissing S. Solid lipid nanoparticles (SLN) and nanostructured lipid carriers (NLC) in cosmetic and dermatological preparations. Adv Drug Deliv Rev. 2002;54:S131-S155.

39. Ishida T, Wang X, Shimizu T, Nawata K, Kiwada H. PEGylated liposomes elicit an anti-PEG IgM response in a T cell-independent manner. $J$ Control Release. 2007;122(3):349-355.

40. Mond JJ, Lees A, Snapper CM. T cell-independent antigens type 2 . Annu Rev Immunol. 1995;13(1):655-692.

41. Mond JJ, Vos Q, Lees A, Snapper CM. T cell independent antigens. Curr Opin Immunol. 1995;7(3):349-354.

42. Joshi MD, Müller RH. Lipid nanoparticles for parenteral delivery of actives. Eur J Pharm Biopharm. 2009;71(2):161-172.

43. Liu K, Sun J, He Z-g. Development on novel nanostructured lipid carriers. J Shenyang Pharm Univ. 2008;3:017.

44. Cheng T-L, Chen B-M, Chern J-W, Wu M-F, Roffler SR. Efficient clearance of poly(ethylene glycol)-modified immunoenzyme with anti-PEG monoclonal antibody for prodrug cancer therapy. Bioconjug Chem. 2000;11(2):258-266.

45. Cheng T-L, Wu P-Y, Wu M-F, Chern J-W, Roffler SR. Accelerated clearance of polyethylene glycol-modified proteins by anti-polyethylene glycol IgM. Bioconjug Chem. 1999;10(3):520-528.

46. Li S-D, Huang L. Stealth nanoparticles: high density but sheddable PEG is a key for tumor targeting. J Control Release. 2010;145(3):178.

47. Needham D, Stoicheva N, Zhelev DV. Exchange of monooleoylphosphatidylcholine as monomer and micelle with membranes containing poly(ethylene glycol)-lipid. Biophys J. 1997;73(5):2615-2629.

48. Garbuzenko O, Barenholz Y, Priev A. Effect of grafted PEG on liposome size and on compressibility and packing of lipid bilayer. Chem Phys Lipids. 2005;135(2):117-129.

49. Torchilin VP, Omelyanenko VG, Papisov MI, et al. Poly(ethylene glycol) on the liposome surface: on the mechanism of polymer-coated liposome longevity. Biochim Biophys Acta. 1994;1195(1):11-20.

50. Basten A, Silveira PA. B-cell tolerance: mechanisms and implications. Curr Opin Immunol. 2010;22(5):566-574.

51. Hashimoto Y, Shimizu T, Mima Y, Abu Lila AS, Ishida T, Kiwada H. Generation, characterization and in vivo biological activity of two distinct monoclonal anti-PEG IgMs. Toxicol Appl Pharmacol. 2014; 277(1):30-38. 


\section{Supplementary materials \\ Hematological analysis}

Method

Beagle dogs were injected with PE (PEGylated emulsions) via a vein in the right forelimb at a phospholipid dose of $2.5 \mu \mathrm{mol} / \mathrm{kg}$. Before the injection, a blank blood sample was collected from the left forelimb. Blood samples were collected immediately in the right forelimb after the first injection, regarded as $0 \mathrm{~min}$. At 1, 3, 5, and $10 \mathrm{~min}$ after the intravenous injections, blood samples were obtained from the right forelimb, except at 3 and 5 min when blood samples were collected from the left forelimb. All blood samples were collected in bottles containing ethylenediaminetetraacetic acid dipotassium salt (EDTA-2K) and analyzed using a hematology analyzer (LH-750, Beckman Coulter, Inc., Brea, CA, USA). Ratios between measured values and blank blood samples were calculated at each time point, designated $Q$, which is expressed by the following equation:

$$
Q \%=\frac{Q_{t}}{Q_{0}} \times 100
$$

where $Q_{t}$ is the determination of blood samples and $Q_{0}$ is the blank blood sample.

\section{Results and discussion}

As shown in Figure S1A, immune cells immediately gathered in the injected limb, and the number of monocytes, leukocytes, lymphocytes, and neutrophilic granulocytes at the injection site increased by $467 \%, 326 \%, 320 \%$, and $306 \%$, respectively. The amount of immune cells returned to the baseline level within 3-5 min of administration. The number of immune cells on the side opposite to the injection site was reduced to below $50 \%$ of the control at 3 min after
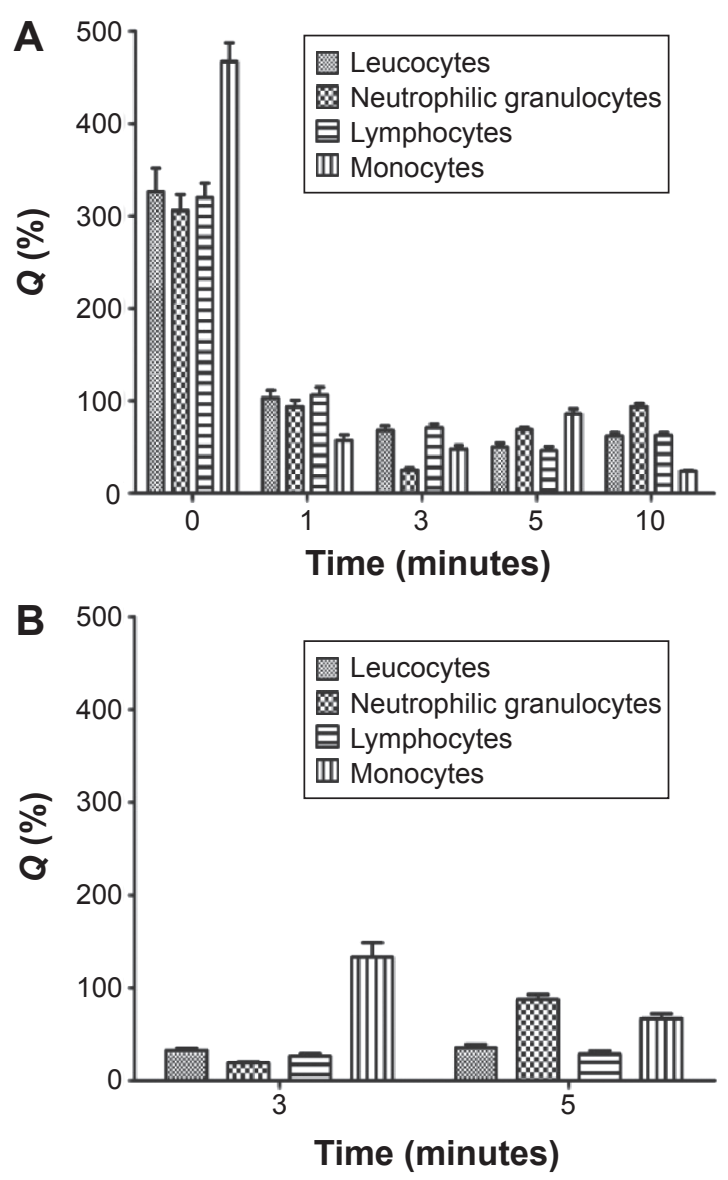

Figure SI The percentage change in leucocytes, neutrophilic granulocytes, monocytes, and lymphocytes in left and right limbs after the intravenous injection. Notes: The beagle dogs were treated with PE at a dose of $2.5 \mu \mathrm{mol}$ phospholipid $/ \mathrm{kg}$. Right limb (A); left limb (B). Data show mean \pm standard deviation of three repeats. $Q \%=\left(Q_{t} / Q_{0}\right) \times 100$, where $Q_{t}$ is the value for the blood sample and $Q_{0}$ is the control value.

Abbreviation: PE, PEGylated emulsions.

the injection, whereas the number of immune cells in the injected limb and in limb opposite to the injected limb returned to the baseline levels at $5 \mathrm{~min}$ after the injection (Figure S1B).
International Journal of Nanomedicine

\section{Publish your work in this journal}

The International Journal of Nanomedicine is an international, peerreviewed journal focusing on the application of nanotechnology in diagnostics, therapeutics, and drug delivery systems throughout the biomedical field. This journal is indexed on PubMed Central, MedLine, CAS, SciSearch ${ }^{\circledR}$, Current Contents ${ }^{\circledR} /$ Clinical Medicine,

\section{Dovepress}

Journal Citation Reports/Science Edition, EMBase, Scopus and the Elsevier Bibliographic databases. The manuscript management system is completely online and includes a very quick and fair peer-review system, which is all easy to use. Visit http://www.dovepress.com/ testimonials.php to read real quotes from published authors. 